\title{
Liquefaction and Settlement Analysis of Silt Soil Foundation in High Earthquake Intensity Region
}

\author{
ZHANG Huanqiang ${ }^{1,}$,, XIANG Xiaohui ${ }^{2, b}$ \\ ${ }^{1}$ Changjiang Institute of Survey, Planning, Design and Research, Wuhan, Hubei, China \\ ${ }^{2}$ China Railway Siyuan Survey and Design Group Co., Ltd., Wuhan, Hubei, China \\ azhanghuanqiang@cjwsjy.com.cn, ${ }^{b}$ xiangxiaoh@mails.gucas.ac.cn
}

Keywords: silt soil foundation, seismic liquefaction, differential settlement, numerical simulation. Abstract. The under-crossing tunnel of east external ring of Kunming is one of the most important projects of the Kunming south railway station hub construction. Two layers of silt soil are found in tunnel mileage $\mathrm{K} 2+100-\mathrm{K} 2+200$ and one of them is just under the tunnel floor. Since the project is on high seismic intensity region and the silt soil foundation is easy to be liquefied, it is important to analysis the liquefaction and settlement of the silt soil foundation. In the paper, the whole process of silt soil foundation liquefaction and settlement analysis is presented based on finite difference method. The results indicate that the silt soil foundation will not be liquefied under the design seismic load and the settlement of the silt soil foundation is satisfied.

\section{Introduction}

With the high speed of infrastructure constructions in China, more and more highways and tunnels are constructed on soft foundations and in high seismic intensity regions. On the one hand, the soft foundation has low bearing capacity and large consolidation settlement; on the other hand, under the seismic action, the large foundation settlement caused by seismic liquefaction will induce the failure of engineering structures. Therefore, it is required to perform seismic analysis of soft foundation in high earthquake intensity regions[1-3].

This paper takes the east outer ring road tunnel project of Kunming as an example. In the process of investigation, two layers of silt soil, $11 \mathrm{~m}$ thick and $14 \mathrm{~m}$ thick respectively, were found in the tunnel mileage from $\mathrm{K} 1+900$ to $\mathrm{K} 2+380$, where the $14 \mathrm{~m}$ thick layer of silt soil was just under the tunnel floor. Since the project is in 8-degree earthquake intensity region, and the silt soil foundation has low bearing capacity and under the action of earthquake it is easy to be liquefied, the seismic performance of the tunnel foundation should be analyzed.

\section{Engineering Background}

The total tunnel length of Kunming east outer ring road is $2040 \mathrm{~m}$, with starting mileage K0+600 and ending mileage $\mathrm{K} 2+640$. The earthquake fortification is designed with peak ground acceleration (PGA) of $0.20 g$.

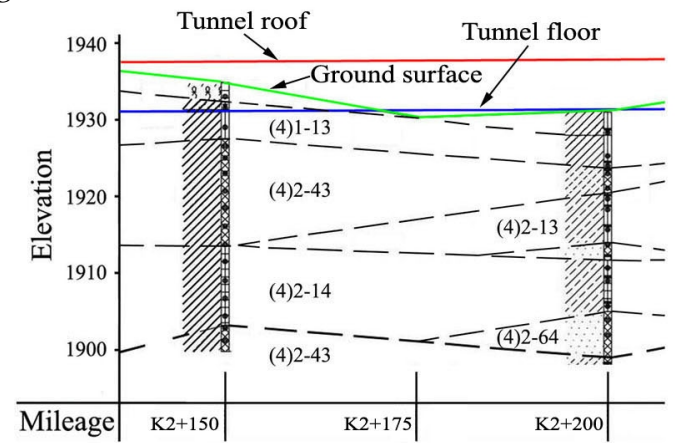

(a)

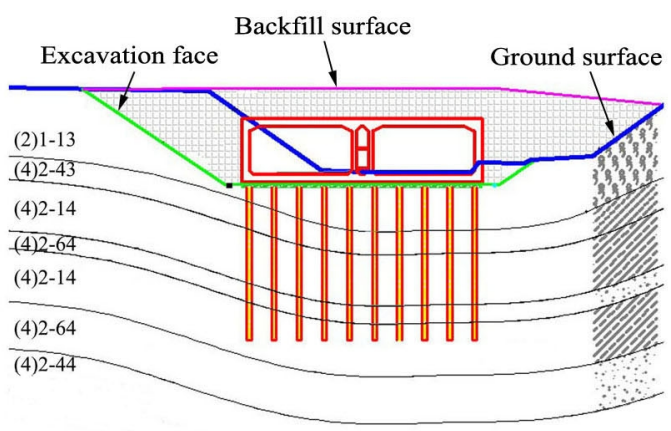

(b)

Fig. $1 \mathrm{~K} 1+900-\mathrm{K} 2+380$ mileage profiles: (a) longitudinal profile; (b) cross-sectional profile 
As shown in Fig. 1, within the mileage from $\mathrm{K} 1+900$ to $\mathrm{K} 2+380$, there are two layers of silt soil (stratum number: (4)2-43) with thickness of $11 \mathrm{~m}$ and $14 \mathrm{~m}$ respectively, where the $14 \mathrm{~m}$ thick layer of silt soil is just under the tunnel floor. The PHC pipe piles with diameter of $500 \mathrm{~mm}$ and wall thickness of $125 \mathrm{~mm}$ are adopted as foundation reinforcement. The spacing distance of the PHC pipe piles are $3.2 \mathrm{~m}$ in both cross-sectional and longitudinal directions. The tunnel linings are cast-in-place with C35 concrete. The thickness of tunnel roof, floor, side walls and middle wall is $1.0 \mathrm{~m}, 1.2 \mathrm{~m}, 1.0 \mathrm{~m}$ and $0.6 \mathrm{~m}$ respectively.

\section{Model Description}

The geometry model is set up using the typical profiles as shown in Fig. 1. In dynamic analysis, the mesh size has direct influence on the computation precision, and the numerical model cannot be entirely in agreement with the actual project, it is necessary to do some simplifications in modelling. Some thin stratums are merged and some irregular stratums are regularized. However, the silt soil stratum are kept the original feature. The size of each stratum is shown in Fig. 2(unit: meter).

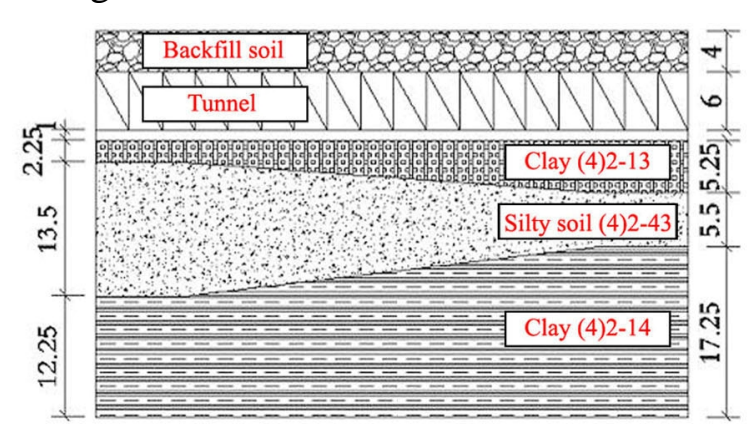

(a)

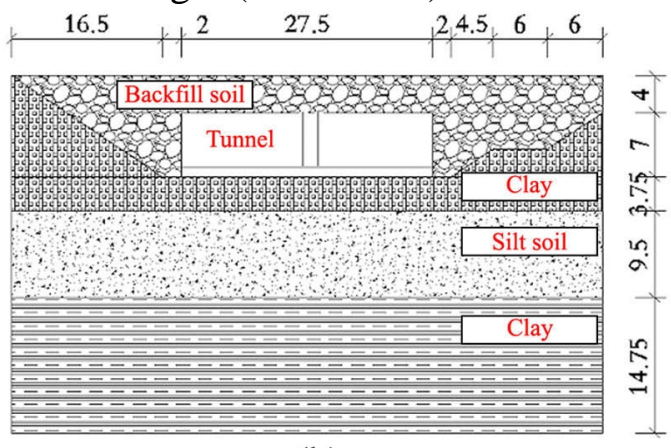

(b)

Fig. 2 Geometry model profiles: (a) longitudinal profile; (b) cross-sectional profile

Fig. 3 demonstrates the arrangement of PHC pipe piles and the tunnel structure. The three dimensions (length, width and height) of the geometry model are $60 \mathrm{~m}, 64.5 \mathrm{~m}$ and $39 \mathrm{~m}$.

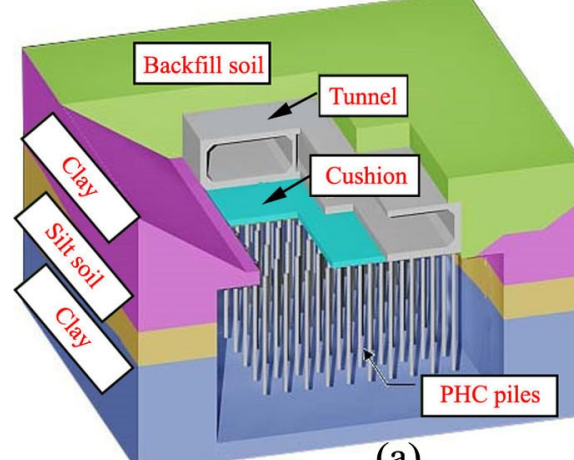

(a)

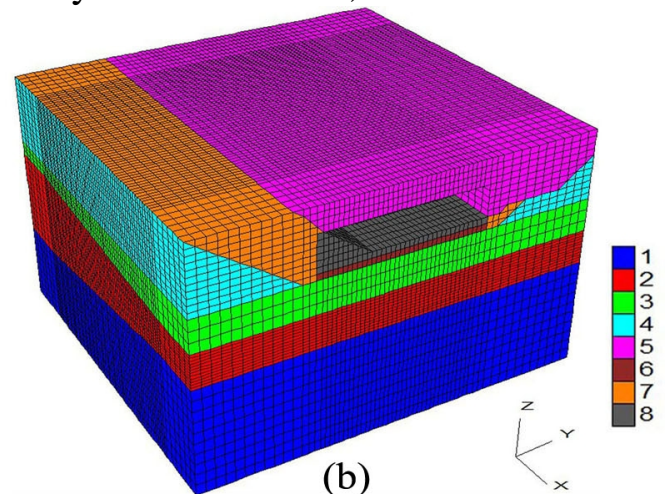

(b)

Fig. 3 Three-dimensional models: (a) geometry model; (b) numerical model

FLAC3D software is adopted in the numerical modelling. It can simulate different geotechnical engineering conditions, such as excavation, large deformation, seepage and dynamic analysis and the simulation results are reliable and applicable which have been widely proved[4-6]. In this paper, the soil liquefaction which involves both seepage and dynamic analysis, can be easily simulated in FLAC3D. It provides the Finn model for soil liquefaction analysis, which has been widely used in the study of liquefaction.

In dynamic analysis, the wave propagation is directly related to the input wave frequencies and the soil properties. Research works by Lysmer and Kuhlemeyer[7] show that in order to accurately describe the wave propagation, the mesh size must be less than 1/8-1/10 of the minimum wave length, because if the mesh size is too large, high frequency waves can hardly pass through.

Since the simulated model is mainly composed of soft soils which has small modulus, the wave length of the high frequency part of the earthquake wave can be very small. Besides, the simulated 
model size is relatively big which will result in huge element number. In order to keep better computational feasibility and accuracy, as shown in Table 1, the mesh size of the silt soil stratum is set to $1 / 8$ of the wave length, and the other stratums are set to $1 / 4$ of the wave length.

Table 1 Mesh size control

\begin{tabular}{cccccc}
\hline \multirow{2}{*}{ Stratum } & Wave velocity & Wave frequency & Wave length & \multicolumn{2}{c}{ Element size $[\mathrm{m}]$} \\
& $v_{\mathrm{s}}[\mathrm{m} / \mathrm{s}]$ & $F[\mathrm{~Hz}]$ & $\Delta L[\mathrm{~m}]$ & $1 / 8 \Delta L$ & $1 / 4 \Delta L$ \\
\hline Backfill soil & 75.3 & & 7.53 & 0.94 & 1.88 \\
Clay (2)1-13 & 60.9 & \multirow{2}{*}{10} & 6.09 & 0.76 & 1.52 \\
Silt soil (4)2-43 & 60.8 & & 6.08 & 0.76 & 1.52 \\
Clay (4)2-14 & 67.7 & & 6.77 & 0.85 & 1.61 \\
\hline
\end{tabular}

According to the control size in Table 1, the element size of the silt soil stratum is $0.75 \mathrm{~m}$, the others are $1.5 \mathrm{~m}$. In FLAC3D, the PHC pipe pile and tunnel lining are simulated using pile and shell structural elements respectively.

The ideal Mohr-Coulomb elastic-plastic model is adopt in the numerical simulation. The physical and mechanical parameters are shown in Table 2, Table 3 and Table 4. All stratums have no tensile strength. The Biot coefficient is 1.0 and the fluid modulus is $200 \mathrm{MPa}$.

Table 2 Mohr-Coulomb model parameters

\begin{tabular}{ccccc}
\hline Stratum & Shear modulus [MPa] & Bulk modulus [MPa] & Cohesion $[\mathrm{kPa}]$ & Fraction angle $\left[{ }^{\circ}\right]$ \\
\hline Backfill soil & 7.60 & 12.67 & 39.91 & 13.21 \\
Clay (2)1-13 & 4.81 & 14.44 & 24.78 & 10.01 \\
Silt soil (4)2-43 & 5.77 & 12.50 & 5.80 & 23.21 \\
Clay (4)2-14 & 6.80 & 11.33 & 38.71 & 11.06 \\
\hline
\end{tabular}

Table 3 Stratum permeability parameters

\begin{tabular}{cccc}
\hline Stratum & Dry density $\left[\mathrm{g} / \mathrm{cm}^{3}\right]$ & Void ratio & Permeability coefficient \\
\hline Backfill soil & 1.34 & 1.10 & $1.25 \mathrm{E}-6$ \\
Clay (2)1-13 & 1.30 & 1.21 & $6.77 \mathrm{E}-7$ \\
Silt soil (4)2-43 & 1.56 & 0.79 & $1.20 \mathrm{E}-3$ \\
Clay (4)2-14 & 1.48 & 0.93 & $7.52 \mathrm{E}-7$ \\
\hline \multicolumn{5}{c}{ Table 4 Dynamic analysis parameters } \\
\hline Stratum & Damping & Damping coefficient & Finn parameter \\
\hline Backfill soil & 0.051 & 0.161 & \\
Clay (2)1-13 & 0.042 & 0.132 & $C_{1}=0.295$, \\
Silt soil (4)2-43 & 0.029 & 0.090 & $C_{2}=1.357$ \\
Clay (4)2-14 & 0.037 & 0.116 & \\
\hline
\end{tabular}

The PHC pipe pile parameters are: Young's modulus 28.5GPa, Poisson's ratio 0.21 , density $1.875 \mathrm{~g} / \mathrm{cm}^{3}$, shear spring cohesion $79 \mathrm{kN} / \mathrm{m}$, shear spring fraction angle $5^{\circ}$, shear spring stiffness $63 \mathrm{MPa}$, normal spring cohesion $90 \mathrm{kN} / \mathrm{m}$, normal spring fraction angle $5^{\circ}$ and normal spring stiffness $19 \mathrm{MPa}$. The phreatic surface is just below the tunnel floor.

The three principle stresses should be equal to the pore water pressure when the soil is liquefied. In numerical simulation, the excess pore water pressure ratio is often used as liquefaction indicator. As shown in Eq. 1, where $r_{\mathrm{u}}$ is the excess pore water pressure ratio, $\sigma_{\mathrm{m}}$ is the mean effective stress in calculating process and $\sigma_{\mathrm{m} 0}$ is the initial mean effective stress. Eq. 1 indicates that if $r_{\mathrm{u}}$ equals to 1 , the soil is liquefied, otherwise, the soil is not liquefied.

$$
r_{\mathrm{u}}=1-\sigma_{\mathrm{m}} / \sigma_{\mathrm{m} 0}
$$

\section{Simulation Results}

Without ground motion records, artificial earthquake wave is adopted in the dynamic analysis. As shown in Fig. 4, the PGA of the artificial earthquake wave is $0.2 g$, the duration time is $22 \mathrm{~s}$ and the main 
frequency range is $0 \mathrm{~Hz}-10 \mathrm{~Hz}$. The baseline drift of velocity and displacement time histories has been revised in the simulation.
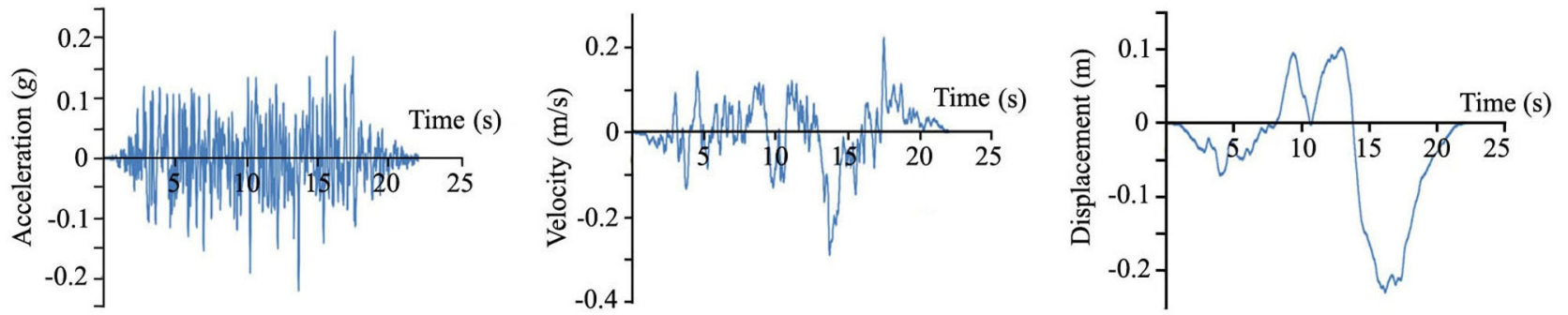

Fig. 4 The artificial earthquake wave

The dynamic analysis is performed by using the numerical model in Fig. 3(b). As shown in Fig. 5(a), three measuring points, i.e., Y1, Y2 and Y3, are located in the silt soil stratum to record the variation of the excess pore water pressure ratio $r_{\mathrm{u}}$. Fig. 5(b) shows that during the time of $2.5 \mathrm{~s}-5.0 \mathrm{~s}$ and $12.0 \mathrm{~s}-16.0 \mathrm{~s}, r_{\mathrm{u}}$ increases notably, and during the last four seconds, $r_{\mathrm{u}}$ changes slightly. At the end of the artificial earthquake, $r_{\mathrm{u}}$ of Y2 measuring point reaches the maximum value 0.207 .

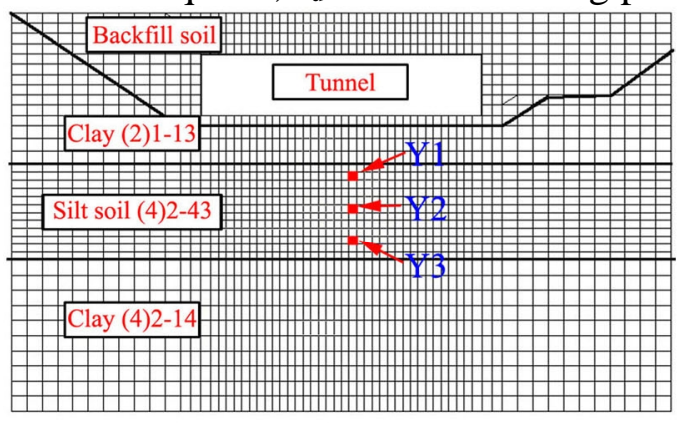

(a)

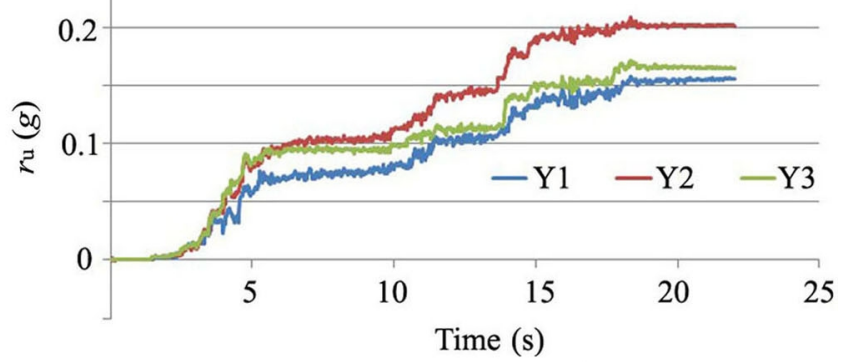

(b)

Fig. $5 r_{\mathrm{u}}$ measurement: (a) $r_{\mathrm{u}}$ measuring point arrangement; (b) $r_{\mathrm{u}}$ vs time curve

Fig. 6 shows the distribution of $r_{\mathrm{u}}$ at the end time of the artificial earthquake when the maximum value of $r_{\mathrm{u}}$ occurs. It can be seen that the value of $r_{\mathrm{u}}$ in the silt soil is obviously higher than that in other stratums which indicates the Finn model setting of the silt soil stratum is valid. The maximum values of $r_{\mathrm{u}}$ mainly appear in the silt soil layer underneath the tunnel. The $r_{\mathrm{u}}$ values change between 0 to 0.2 which indicates that under the action of artificial earthquake the silt soil will not be liquefied.

Fig. 7 shows the settlement contour map. The settlement value varies gradually in diagonal direction and the maximum value is about $25 \mathrm{~mm}$. The differential settlement value is $21.5 \mathrm{~mm}$ for point $\mathrm{A}$ and $\mathrm{B}$ and $15.9 \mathrm{~mm}$ for point $\mathrm{C}$ and $\mathrm{D}$. The differential settlement is relatively low which indicates that under the artificial earthquake, the differential settlement will not cause the failure of tunnel structure.

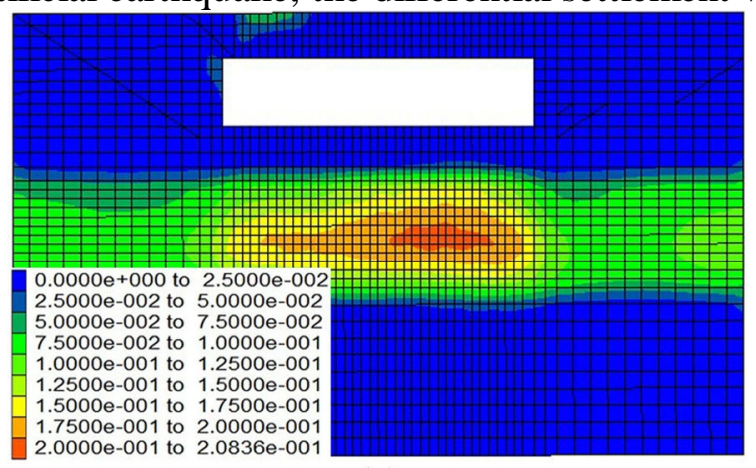

(a)

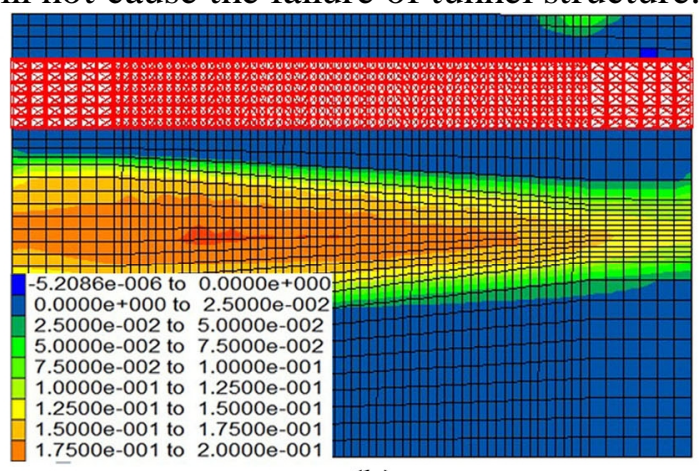

(b)

Fig. 6 Contour map of $r_{\mathrm{u}}$ : (a) longitudinal distribution; (b) cross-sectional distribution 


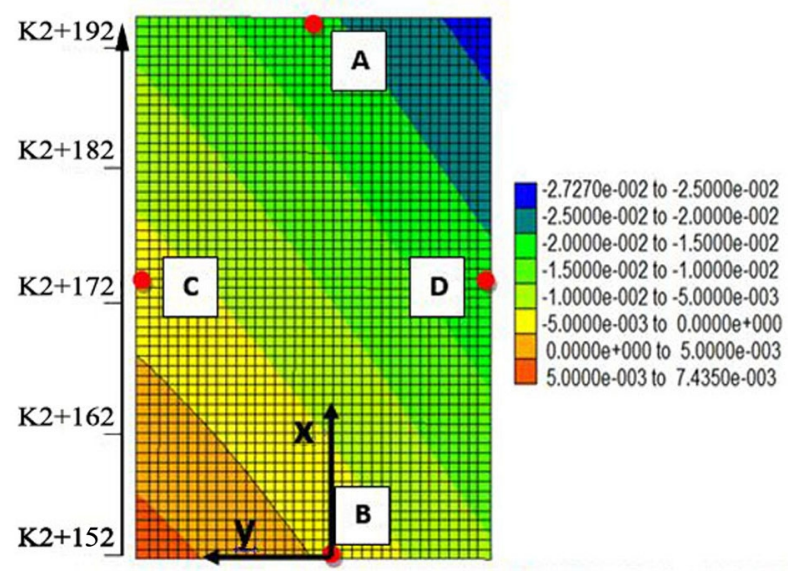

Fig. 7 Longitudinal settlement contour map

\section{Conclusions}

Through the simulation and analysis of the soft soil foundation under artificial seismic loading, we come to the following conclusions:

1. At the end of the artificial earthquake wave, excess pore water pressure ratio reaches its maximum value which is about 0.2 in the simulation. The foundation liquefaction will not occur under the designed seismic load.

2. At the end of the artificial earthquake wave, the settlement value is diagonal distributed and varies uniformly along the diagonal direction. The differential settlement is relatively low which indicates that under the designed seismic load, the differential settlement will not cause the failure of tunnel structure.

\section{Acknowledgments}

This work was financially supported by Open Research Fund of State Key Laboratory of Geomechanics and Geotechnical Engineering, Institute of Rock and Soil Mechanics, Chinese Academy of Sciences (Z015009).

\section{References}

[1] M. Jefferies. K. Been: Soil Liquefaction: A Critical State Approach (Taylor \& Francis, 2006).

[2] M. Seidkarbasi, P.M. Byrne: Can. Geotech. J. 2007, Vol. 44 (2007), p. 873-890.

[3] P.K. Robertson, C.E. Fear, in: Proceedings of the 1st International Conference on Earthquake Geotechnical Engineering, edtied by K. Ishihara, A.A. Balkema/Rotterdam/Brookfield, Tokyo, Japan (1995).

[4] M. Askoy, G. Once, in: Proceedings of the 3rd International FLAC Symposium, edtied by R. Brummer, et al., Swets and Zeitinger, Sudbury, Canada (2003).

[5] H. Hakami: Int. J. Rock Mech. Min. Sci. Vol. 38 (2001), p. 59-65.

[6] V. Hajiabdolmajid, P. Kaiser: Tunn. Undergr. Sp. Tech. Vol. 18 (2003), p. 35-48.

[7] J. Lysmer, R.L. KuhlemeyerLysmer: J. Eng. Mech. Div. ASCE. Vol. 95 (1969), p. 859-878. 